\section{Vigabatrin associated visual field loss: a clinical audit to study prevalence, drug history and effects of drug withdrawal}

WD Newman, K Tocher and JF Acheson

\begin{abstract}
Purpose To survey clinical visual function including quantitative manual perimetry results in a group of patients taking vigabatrin; to assess the severity of any field defects; to tabulate cumulative and daily doses of medication and to assess possible changes in visual function over time.

Method A prevalence study of 100 out of 183 patients currently attending a tertiary referral epilepsy centre who were taking or had recently discontinued vigabatrin (duration 83-3570 days; mean 1885 days) as part of combination anticonvulsant therapy. Complete neuro-ophthalmic examination including Goldmann kinetic perimetry was performed and monocular mean radial degrees (MRD) to the $\mathrm{I} / 4 \mathrm{e}$ isopter calculated. Patients were followed up at 6-monthly intervals for not less than 18 months.

Results Acuity and colour vision remained stable in all patients regardless of changes in visual fields. Twenty per cent of patients had significant constriction of their visual field defined as a monocular MRD of $\mathbf{3 0}$ degrees or less. Males were significantly more likely to be severely affected than females $(P<0.01)$. Twenty one patients were followed after discontinuing vigabatrin treatment. Only three of these showed a change in MRD of $\mathbf{1 0}$ degrees or more with two deteriorating and one improving. No correlation between treatment duration or cumulative dosage $/ \mathrm{kg}$ and the severity of defects could be demonstrated.

Conclusions Earlier reports of a high prevalence of both moderate and more serious field defects were confirmed in patients taking vigabatrin but not in epileptic patients taking other anti-
\end{abstract}

convulsants. We found no evidence of progression or resolution of visual field defects on discontinuing the drug, and no relationship between dose history and visual deficit field loss. An idiosyncratic drug reaction within the neurosensory retina may underlie the pathogenesis of the visual field loss in some patients Eye (2002) 16, 567-571. doi:10.1038/ sj.eye. 6700168

Keywords: vigabatrin; visual failure; visual fields

\section{Introduction}

Vigabatrin (Sabril, Hoechst Marion Roussel/Aventis Ltd) was introduced into UK clinical practice on a trial basis in the mid1980s and granted a licence in 1989. Since 1997 numerous reports have appeared describing an association between use of the anticonvulsant and bilateral symmetrical loss of visual field. ${ }^{1-8}$ It is hypothesised that in addition to effects on cerebral function, irreversible inhibition of GABA aminotransferase with consequent elevation of GABA levels in the inner retina is the priniciple cause of the depressed visual function and this is supported by electrophysiological data. ${ }^{9-15}$ Outer retinal and possibly also cortical effects may play a role. ${ }^{12}$ Males may be more susceptible than females ${ }^{11}$ but the role of other risk factors such as cumulative dosage is less clear. There are reports of visual recovery after drug withdrawal ${ }^{16,17}$ but in a larger study of 13 patients, Johnson et al found no association between the recovery of visual function and either treatment duration or cumulative dosage. ${ }^{18}$
Dept of Neuroophthalmology, National Hospital for Neurology \& Neurosurgery Queen Square

London WC1N 3BG, UK

Correspondence: JF Acheson MRCP FRCOphth

Dept of Neuroophthalmology National Hospital for Neurology \& Neurosurgery Queen Square London WC1N 3BG, UK Tel: +44 (0)20 78373611 ext 3388

Fax: +44 (0)20 76762041 E-mail: jacheson@uclh.org 
As part of an on-going surveillance and audit exercise on visual field loss associated with vigabatrin in a population of 183 patients attending a tertiary referral epilepsy clinic conducted since 1998, we have collected data on drug history and visual performance on kinetic perimetry. We report our observations on the relationship between total dosage of vigabatrin and the presence of field defects, and the consequences of discontinuing the drug.

\section{Patients and methods}

The study commenced in March 1999. All patients who were currently, or had in the past, taken vigabatrin as part of combination anticonvulsant therapy and were attending the epilepsy clinic at the National Hospital for Neurology and Neurosurgery, London or the National Society for Epilepsy at Chalfont, Bucks, UK were identified and referred for ophthalmological assessment.

Each patient was interviewed using a standardised proforma designed to reveal both symptomatic and asymptomatic ocular disease. This included details of past ocular history including family history of ocular disease; refractive history; neurological and neurosurgical history and a drug history. The patients were asked if they had any visual problems, and then graded questions were asked in order to elicit any visual disturbance that might be related to vigabatrin, which included general questions about recent onset of any visual problems, to more direct questions of blurred vision; tunnel vision/restricted peripheral vision/ flickering lights. All the patients had been informed by the referring neurologists that the reason for referral was a suspected link between reduced peripheral vision and vigabatrin.

Best corrected distance (Snellen) and near acuity were recorded. Colour vision was assessed using the 17 number plate version of the Ishihara pseudoisochromatic test. Goldmann kinetic field testing to the I/4e and V/4e isoptres only was performed, with all the tests performed on the same regularly calibrated machine (Haag-Streit, with background luminance of 31.5 apostilbs, and using appropriate full aperture spectacle correction for the central field) by the same experienced perimetrist (KT). Fixation was carefully monitored by direct visualisation of the fixating eye and by rechecking points both outside and inside the area of the apparent seeing field at specific meridians. Automated static perimetry was not used because of unacceptably high poor reliability indices in both our own patient population and others, ${ }^{17}$ using full-threshold stategies and the lack of validated scoring systems for analysis of suprathreshold screening programmes. Analysis of the kinetic visual field data was done by measuring the radial distance in degrees at each of 12 points, 30 degrees apart, of the $\mathrm{I} / 4 \mathrm{e}$ isoptre of the visual field. The mean peripheral field diameter was then determined and the results expressed as mean radial degrees (MRD) averaged for each eye of each patient and compared to those obtained from controls. This method follows the techniques described in the NIH-sponsored Diabetic Retinopathy Trial in $1981^{19}$ and latterly used in the study of vigabatrin-associated visual field loss by Krauss, Johnson and co-workers. ${ }^{11,18,20}$

All patients were then examined by an ophthalmologist (JFA or WDN) who were masked to the findings of the visual field examination. Each patient underwent a full neuro-ophthalmic examination to assess any possible visual or ocular comorbidity including pupillary responses, anterior segment biomicroscopy at the slit lamp and both direct and indirect fundus examination following pupillary dilatation with tropicamide $1 \%$.

Patients were then given rolling 6-month follow-up appointments. At subsequent visits changes to medication were noted and any new visual symptoms were enquired of. A repeat examination of best corrected visual acuity for near and distance, colour vision, and pupillary responses was carried out prior to performing a visual field test as described at their first attendance. The visual fields were undertaken by the same perimetrist (KT). Control data were obtained from a group of 10 patients with epilepsy taking other anticonvulsants who had never taken vigabatrin and a group of 10 healthy volunteers.

The visual field data were analysed as a continuous variable using a commercially available statistically package (SPSS). Only values from the right eye were used in the analysis. In addition, the visual fields were also arbritrarily assigned into those who had significant visual field defects (visual field of 30 or less mean radial degrees) and those who did not (with a visual field of more than $30 \mathrm{MRD}$ ). This level of field loss was believed likely to reflect clinically significant loss of function although we were unable to test this assumption more fully.

\section{Results}

\section{The patients}

One hundred and eighty-three patients were invited for examination; 14 failed to attend. One hundred and sixty-nine patients were examined, 94 male and 79 female with a mean age of 37 years (range: 17-79, median 37 years). The following patients were 
excluded from the data analysis: 17 patients who were unable to complete visual field assessment due to cognitive impairment; six patients with pre-existing ocular pathology which could affect visual field results (either glaucoma or age-related macular degeneration); 26 patients who had visual field defects arising from previous intra-cranial surgery for epilepsy; and 14 who had pre-existing intra-cranial tumours.

The data from the remaining 100 patients (54 male and 46 female) were used for analysis. The patients' ages ranged from 18 to 68 years with an average age of 38 years (median 37 years), the mean treatment period with vigabatrin was 1833 days (range 83-4387 days) with a mean daily dose of $2 \mathrm{~g}$ (range $0.5-4.0 \mathrm{~g}$ ). The cumulative total dose at first neuro-ophthalmic assessment was recorded for all patients; estimated mean total dose of $4029 \mathrm{~g}$ (range 166-17548 g).

\section{Ophthalmological examination}

All patients had a best corrected distance acuity of $6 / 9$ and N8 or better for near. Colour vision was assessed with the Ishihara colour plates, a presumed congenital $\mathrm{red} /$ green deficit was found in four males. Otherwise all patients managed 15 of the 17 plates correctly (mean 16.5). The control subjects all had a visual acuity of 6/6 and N5 and read all 17 colour plates correctly.

No patient had a relative afferent pupillary defect, and examination of the fundi did not reveal any optic disc pallor or significant macular abnormalities.

\section{Visual fields}

The two control populations had a mean visual field of 55.5 MRD (range 47.0-60.0 MRD, SD 3.7) and there was no significant difference between the two groups. The vigabatrin-treated group on the other hand showed a significantly different mean visual field of 38.5 MRD (range 5.0-58.3 MRD, SD 10.5, $P<0.01$ unpaired $t$-test) (Figure 1).

Twenty patients fell into the category of having a severe visual field defect (VF $\leqslant 30 \mathrm{MRD}$ ) with a mean age 41 years (median 41.5 years, SD 12.8 years) of

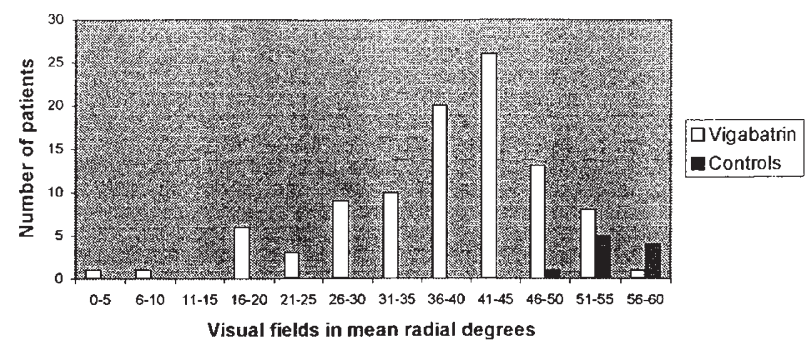

Figure 1 MRD in vigabatrin patients and in controls. whom six were female and 14 were male. They had on average been taking vigabatrin for 1943 days (median 1668 days) and had taken a mean estimated total of $5380 \mathrm{~g}$. This compares with the group with visual fields of 31 MRD or greater who had a mean age of 37 years (median 35.5 years, SD 10.5) of whom 40 were female and 40 male. These patients had taken a mean estimated total of $4574 \mathrm{~g}$ and had been on the drug for a mean time of 2758 days. Analysis of variance revealed no significant difference between the total amount of drug consumed by the two groups $(F=0.5$, $P=0.48)$, or the period of treatment $(F=0.4, P=0.5)$. It is clear however that more men than women were affected by severe visual loss; this was both clinically and statistically significant with an odds ratio of 2.3 $\left(\chi^{2}=5.79, \mathrm{df}=1, P<0.01\right)$. When comparing these 20 men and women there was no difference in the amount of drug consumed ( $P=0.27$, unpaired $t$-test) or age of the individuals ( $P=0.08$, unpaired $t$-test).

\section{Follow-up period}

One hundred patients attended for the baseline investigation, they were then booked for a further assessment 6 months later. Seventy patients had been assessed at 6 months; 49 at 12 months and 22 at 18 months.

Comparing the follow-up visual fields with those at first attendance, a small improvement was seen with subsequent visits, but this does not reach statistical significance $(P>0.05$ in each case using paired $t$-test).

\section{What happened when the vigabatrin was stopped?}

Twenty-one patients discontinued vigabatrin; eight prior to the initial assessment and 13 during the follow-up period. Eighteen demonstrated no significant change and three showed greater than 10 degree (MRD) change with improvement in one patient and deterioration in two. There was no significant change in MRD between the first and last visits ( $t$-test $P=0.39$ ). In this sub-group data on cumulative dosage/ $\mathrm{kg}$ were available. There was no correlation between cumulative dosage/ $\mathrm{kg}$ and MRD (regression analysis $r^{2}=0.04$ and analysis of variance $P=0.38$ ) or duration of treatment at first visit and MRD (regression analysis $r^{2}=0.04$ and analysis of variance $P=0.38$ ) (Table 1).

\section{Discussion}

A high proportion of patients (17 out of $166=10 \%$ ) could not perform manual kinetic perimetry satisfactorily because of cognitive problems and had to 
Table 1 Effects of discontinuing vigabatrin

\begin{tabular}{|c|c|c|c|c|c|c|c|c|c|}
\hline$I D$ & Sex & Age & Other drugs & & $\begin{array}{l}\text { Time in } \\
\text { months on } \\
\text { vigabatrin }\end{array}$ & $\begin{array}{c}\text { Follow-up } \\
\text { in months } \\
\text { after } \\
\text { stopping }\end{array}$ & $\begin{array}{c}\text { Cumulative } \\
\text { dose } \mathrm{g} / \mathrm{kg}\end{array}$ & $\begin{array}{c}\text { Visual field } \\
\text { at first visit } \\
\text { Right eye } \\
\text { MRD }\end{array}$ & $\begin{array}{c}\text { Visual field } \\
\text { at last visit } \\
\text { Right eye } \\
\text { MRD }\end{array}$ \\
\hline 1 & $\mathrm{M}$ & 46 & PRM, PHT & & 22 & 25 & 12 & 10 & 15 \\
\hline 2 & M & 43 & PRN, PHT & $\mathrm{s}$ & 42 & 19 & 38 & 23 & 23 \\
\hline 3 & M & 42 & CBZ & & 120 & 4 & 128 & 17 & 21 \\
\hline 4 & $\mathrm{M}$ & 38 & CBZ, LTG, CLO & & 62 & 7 & 40 & 28 & 37 \\
\hline 5 & $\mathrm{M}$ & 54 & PHT, LTG & & 72 & 8 & 65 & 16 & 35 \\
\hline 6 & $\mathrm{M}$ & 49 & CBZ, TIA, FRU, CLO & s & 24 & 78 & 30 & 16 & 25 \\
\hline 7 & $\mathrm{M}$ & 60 & CBZ, TOP & & 72 & 14 & 52 & 20 & 26 \\
\hline 8 & $\mathrm{M}$ & 51 & CBZ & $\mathrm{s}$ & 52 & 19 & 29 & 35 & 28 \\
\hline 9 & $\mathrm{~F}$ & 30 & GAB, PHT, & & 25 & 18 & 19 & 40 & 48 \\
\hline 10 & $\mathrm{~F}$ & 40 & GAB, PRE, & & 56 & 8 & 41 & 42 & 48 \\
\hline 11 & $\mathrm{M}$ & 45 & LAM & $\mathrm{s}$ & 48 & 12 & 50 & 42 & 45 \\
\hline 12 & $\mathrm{M}$ & 35 & CBZ, TOP, LTG & & 30 & 7 & 13 & 41 & 41 \\
\hline 13 & $\mathrm{M}$ & 32 & CBZ, PRM & $\mathrm{s}$ & 72 & 5 & 70 & 44 & 47 \\
\hline 14 & $\mathrm{M}$ & 27 & PHT, PRM, TIA & & 38 & 8 & 21 & 42 & 46 \\
\hline 15 & $\mathrm{~F}$ & 44 & PHT, GAB, CBZ & & 94 & 12 & 12 & 38 & 32 \\
\hline 16 & $\mathrm{M}$ & 43 & GAB, CBZ, TOP & $\mathrm{s}$ & 78 & 25 & 80 & 44 & 43 \\
\hline 17 & M & 25 & PHT, CLO, TIA & $\mathrm{s}$ & 36 & 23 & 32 & 31 & 33 \\
\hline 18 & $\mathrm{M}$ & 42 & CBZ, PHT & & 72 & 12 & 92 & 38 & 50 \\
\hline 19 & $\mathrm{M}$ & 23 & PHT, LAM & & 20 & 14 & 23 & 58 & 43 \\
\hline 20 & $\mathrm{M}$ & 51 & CBZ & & 41 & 9 & 16 & 54 & 28 \\
\hline 21 & $\mathrm{M}$ & 33 & LAM, DIA, TIA & $\mathrm{s}$ & 36 & 45 & 39 & 51 & 50 \\
\hline
\end{tabular}

s, Stopped vigabatrin before first examination. CBZ, carbamazepine. CLO, clobazam. DIA, diazepam. FRU, frusium. GAB, gabapentin,. LAM, lamictal. LTG, lamotrigine. PHT, phenytoin. PRE, prednisolone. PRM, primidone and barbiturates. TIA, tiagabine. TOP, topiramate.

excluded. This high rate may reflect the fact that our study population was by definition refractory to first and second line therapy, used combination therapy and often showed poor performance on other tests of cognitive function. Even higher rates of perimetry failure have been reported elsewhere when automated full threshold strategies were attempted. ${ }^{15}$ A further 20 of our patients $(12 \%)$ had field defects due at least in part to other pathology in the eye or visual pathways and were not studied further.

As an audit and surveillance exercise, the control data in this study were limited to just 10 patients who were on combination anticonvulsant therapy not including vigabatrin, and 10 healthy volunteers. The main purpose of these observations was to validate the calibration of the Goldmann perimetry machine and to confirm reports from others, in particular Lawden and co-workers ${ }^{6}$ showing that significant field defects are not found in non-vigabatrin epileptics. A further limitation imposed by the study design was the lack of any pre-treatment baseline visual assessment. Many of our patients had taken vigabatrin for several years prior to the publication of the first reports of possible visual side-effects in 1997 and some had already discontinued use by the time of their first ophthalmic examination. Therefore our prevalence data (statistically significant reductions in MRD in the vigabatrin-treated patients compared to controls) can only be backed up with limited natural history data. Of interest however, is the fact that in the 21 patients in whom vigabatrin was withdrawn and in whom follow-up examination data were available, there was no evidence of any significant change in field size and no demonstrable relationship to cumulative dosage administered. This is consistent with data published by Johnson et al. ${ }^{18}$ This subgroup included seven of the severely affected with MRDs of 30 degrees or less and significant visual loss.

Research continues on both the pathogenesis of vigabatrin-associated visual field defects and the effects of vigabatrin on retinal function some of which may be independent of field loss. ${ }^{15}$

Our study confirms earlier estimates of a high prevalence of some level of field loss and a $20 \%$ prevalence of major defects likely to correspond to clinically significant visual impairment. The male preponderance, and lack of relationship between visual loss and dosage suggests an idiosyncratic drug reaction. We propose that genetically determined variations in local tissue drug or metabolite deactivation or clearance most probably in the retina are likely to be relevant. 


\section{Acknowledgements}

The authors gratefully acknowledge the financial support of Hoechst, Marion, Roussel/Aventis Pharmaceuticals in the running of this study.

\section{References}

1 Eke T, Talbot JF, Lawden MC. Severe persistent visual field constriction associated with vigabatrin. BMJ 1997; 314: 180-181.

2 Wilson EA, Brodie MJ, Wong IC, Mawer GE, Sander JWAS, Blackwell $\mathrm{N}$ et al. Severe persistent visual field constriction associated with vigabatrin (multiple letters). BMJ 1997; 314: 1693-1695.

3 Harding HFA, Mackenzie R, Klistorner A. Severe persistent visual field constriction associated with Vigabatrin. BMJ 1998; 316: 232-233.

4 Beck RW, Brignell MG, Roubertie A, Bellet H, Echenne B, Krauss GL et al. Vigabatrin-associated retinal cone system dysfunction. Neurology 1998; 51: 1778-1778.

5 Daneshvar H, Racette L, Coupland SG, Kertes PJ, Guberman A, Zackon D. Symptomatic and asymptomatic visual loss in patients taking vigabatrin. Ophthalmology 1999; 106: 1792-1798.

6 Lawden MC, Eke T, Degg C, Harding GF, Wild JM. Visual field defects associated with vigabatrin therapy. J Neurol Neurosurg Psychiatry 1999; 67: 716-722.

7 Russell-Eggitt-IM, Mackey-DA, Taylor-DS, Timms-C, Walker-JW. Vigabatrin-associated visual field defects in children. Eye 2000; 14: 334-339.

8 Manuchehri K, Goodman S, Siviter L, Nightingale S. A controlled study of vigatrin and visual abnormalities. $\mathrm{Br} J$ Ophthalmol 2000; 84: 499-505.

9 Ruether K, Pung T, Kellner U, Schmitz B, Hartmann C, Seeliger M. Electrophysiologic evaluation of a patient with peripheral visual field contraction associated with vigabatrin. Arch Ophthalmol 1998; 116: 817-819.
10 Kalviainen R, Nousiainen I, Mantyjarvi $\mathrm{M}$ et al. Vigabatrin, a GABAergic antiepiletic drug, causes concentric visual field defects. Neurology 1999; 53: 922 926.

11 Miller NR, Johnson MA, Paul SR, Girkin CA, Perry JD, Endres M, Krauss GL. Visual dysfunction in patients receiving vigabatrin: clinical and electrophysiologic findings. Neurology 1999; 53: 2082-2087.

12 Arndt CF, Derambure P, Defoort-Dhellemmes S, Hache JC. Outer retinal dysfunction in patients treated with vigabatrin. Neurology 1999; 52: 1201-1205.

13 Hardus P, Verduin WM, Postma G, Stilma JS, Berendschot TT, van Veelen CW. Long-term changes in the visual fields of patients with temporal lobe epilepsy using vigabtrin. Br J Ophthalmol 2000; 84: 788-790.

14 Coupland SG, Zackron DH, Leonard BC, Ross TM. Vigabatrin effect on inner retinal function. Ophthalmology 2001; 108: 1493-1496.

15 Harding GF, Wild JM, Robertson KA, Rietbrock S, Martinez C. Separating the retinal electrophysiologic effects of vigabatrin: treatment versus field loss. Neurology 2000; 55: 347-352.

16 Krakow K, Polizzi G, Riordan-Eva P, Holder G, MacLeod WN, Fish DR. Recovery of visual field constriction following discontinuation of vigabatrin. Seizure 2000; 9: 287-290.

17 Versino M, Viggiotti P. Reversibility of vigabatrininduced visual field defect. Lancet 1999; 354: 486.

18 Johnson MA, Krauss GL, Miller NR, Medura M, Paul SR. Visual function loss from vigabatrin: effect of stopping the drug. Neurology 2000; 55: 40-45.

19 Diabetic Retinopathy Survey report 6 - Design, Methods and Baseline Results. Investig Ophthalmol Vis Sci 1981; 21: 149-209.

20 Krauss GL, Johnson MA, Miller NR. Vigabatrin-associated retinal cone system dysfunction: electroretinogram and ophthalmologic findings. Neurology 1998; 50: 614-618. 